\title{
Diffusion and Adoption of Technology amongst Small and Medium Enterprises during COVID-19- with a focus on Internet of Things.
}

\author{
Aastha Pandey \\ University of Glasgow \\ aastha.pandey@glasgow.ac.uk
}

\begin{abstract}
The paper is a conceptual study of small and medium sized enterprises (SMEs) technology adoption and diffusion with a focus on impact on IoT adoption during COVID-19. The paper proposes that the pandemic has acted as a legitimizing force for technology adoption and diffusion amongst SMEs. SME's have adopted response strategies to cope with the pandemic that have an impact on their propensity to adopt new technology. This has resulted in increased uncertainty, which can be reduced through the strategies identified in this paper. Through literature review on SME IoT adoption during the pandemic, a gap is identified in current studies. This gap is addressed through the inclusion of case-studies and use-cases. The paper can be used as a reference by SMEs for strategy making to reduce information uncertainty, policy makers to support SMEs as well as academicians for further research.
\end{abstract}

\section{Introduction}

COVID-19 outbreak has had unprecedented impact on businesses and individuals. Overnight, countries went into lockdown with businesses offering necessities namely retail, pharmaceutical, public transport and healthcare staying open. Others, including travel and transport, energy, oil and gas, manufacturing, construction, technology instructed many of their employees to start working from home or adopted procedures that ensured physical distancing as well as limited contact in the work environment. In this situation, companies started looking at technology to help ensure business continuity along with safety for their employees and customers.

Information and communications technology (ICT) and technologies like Internet of Things have been helpful in enabling business continuity and safety. For example, vaccine cold chain monitoring to record safe supply and storage of vaccines, use of occupancy sensors to limit the number of people within the buildings, use of barcode based self-checkout at retail stores, use of Bluetooth low energy (BLE) sensors to monitor factory worker movement and interaction with others. According to a 2020 survey of 400 businesses,
47\% planned to invest more in IoT implementation while $35 \%$ planned to withdraw investments [1]. Depending on the industry and the specific IoT technology being used, COVID-19 has had a legitimating/delegitimating impact on IoT adoption.

This paper discusses the impact of COVID-19 on the diffusion and adoption of technology amongst SMEs, the decision-making strategies that SMEs can use regarding a new technology and its applicability. Basis a literature review, the paper discusses prerequisites stimulating the adoption of IoT during COVID-19, strategies, and tools to enable and measure digitalization, various IoT based applications for SMEs during the pandemic and SME case studies.

\section{COVID-19 as an exogenous force influencing technology adoption and diffusion.}

Exogenous shocks or jolts impact criteria on which legitimacy judgements are based within a social system, raising questions on the judgement's reliability [2]. Forces such as regulatory pressures, competitive pressures, technological pressures, and socio-political pressures catalyze transformation and creation of legitimacy conferring criteria as well as deinstitutionalization [3]. For example, new social norms were constructed and legitimized as a response to the pandemic such as social distancing, covering of face etc. that became a standard practice across geographies. For many organizations, norms like work from home transformed from being employee friendly practice to employee safety practice. In many countries, traditional practices of social gathering and networking after work were temporarily de-institutionalized.

COVID-19 and ensuing worldwide lockdowns have triggered institutional change. SMEs in industries such as retail, travel, entertainment, hospitality, construction, and manufacturing have been the most vulnerable to selection pressures, especially if they were already laggards in ICT uptake and digitalization, reliant on in person interactions, manual labor and brick and mortar models [4]. As a result, SMEs are following one or combination of strategies to survive and thrive in the 
pandemic (Table 1) (Table 2). Digitalized SMEs, in sectors such as grocery, pharmaceuticals, healthcare, IT, legal services etc. were able to respond to new rules and norms with agility.

Diffusion takes place through proliferation of success stories of best practices. Traditionally, there exists a chasm between early market and mainstream market primarily due to the lack of reference base [5]. However, during the pandemic, early adopter SMEs have become sources of knowledge for early majority within the local system, influencing adoption of incremental innovations.

Peers drive the adoption of an innovation, influencers or opinion leaders can drive the diffusion of innovation within their encompassing system. However, they need to be considered legitimate sources of information by followers in the social system. Once legitimated, they can drive diffusion of information. Awareness or knowledge about the technological innovation is typically achieved through information exchange in heterophile groups [6].

Outside existing systems, technology or application which is legitimated through conformance, has a narrow diffusion reach while technology or application which requires the agentic creation of legitimacy has a wide diffusion reach [7] (Table 3).

However, exogenous jolts that impact multiple systems forces the creation of new legitimacy criteria with a common template. Incremental technologies can help with the conformance to newly created norms to achieve normative and pragmatic legitimacy. For example: use cases like self-checkout systems, thermal scanners, service robots have diffused widely across SMEs in different geographies during the pandemic with their potential to enable business continuity. External jolts impact technology diffusion reach by forcing previously passive actors to become active evaluators. Additionally, businesses want to avoid the social cost that accompanies failure to adopt.

Companies are no longer passive observers, they are open to and in some cases actively seeking, solutions that can help them adapt to novel situations with ease. There is a consistent effort to move to a state of stability by decreasing information uncertainty and evolving rules and conditions. Large businesses, professional services organizations, technology service providers and media have become sources of information about innovation, technologies, and other resources. Government bodies provide information on cybersecurity norms to raise awareness of the vulnerabilities that come with digital adoption. Similarly, activists and unions raise awareness about the skills and investments needed to adopt digital technologies and the widening gap between digitalized and traditional organizations. Thus, the pandemic has been a force that has impacted the adoption and diffusion of ICT and related technologies including IoT.

Table 1. SME response strategies for survival

\begin{tabular}{|l|l|}
\hline Strategy & Description \\
\hline Lateral Pivot & $\begin{array}{l}\text { A new way of conducting business- through a change in business model, firm operations, or } \\
\text { customer product such that firms serve new customer segment or the same customer segment in a } \\
\text { new way. This can be enabled through the adoption of technology. }\end{array}$ \\
\hline $\begin{array}{l}\text { Backward } \\
\text { Pivot }\end{array}$ & $\begin{array}{l}\text { Going back in time- rolling back operations through significant layoffs and cutbacks. Adoption of } \\
\text { technologies takes place for meeting compliance requirements. }\end{array}$ \\
\hline Capitalization & $\begin{array}{l}\text { Seeking out investments- from government or financial institutions to sustain current state of the } \\
\text { business as well as invest in technology to adhere to new regulatory norms. }\end{array}$ \\
\hline
\end{tabular}

Table 2. Digitalized SME response strategies

\begin{tabular}{|c|c|}
\hline Strategy & Description \\
\hline $\begin{array}{l}\text { Fast } \\
\text { Forward }\end{array}$ & $\begin{array}{l}\text { Legitimize new digital solutions amongst stakeholders - leveraging the pandemic to push for } \\
\text { acceptability. Streamline and focus efforts on digitalized business where possible. }\end{array}$ \\
\hline $\begin{array}{l}\text { Capture New } \\
\text { Demand }\end{array}$ & $\begin{array}{l}\text { A new way of conducting business - by leveraging the pandemic as an opportunity to supplement } \\
\text { or replace existing streams of revenue. }\end{array}$ \\
\hline
\end{tabular}

Table 3. Legitimation Strategies and Diffusion [7]

\begin{tabular}{|c|c|c|c|}
\hline \multirow{4}{*}{$\begin{array}{l}\text { Technological } \\
\text { Newness }\end{array}$} & & \multicolumn{2}{|c|}{ Market Newness } \\
\hline & & New & Existing \\
\hline & Radical & $\begin{array}{l}\text { Creation } \\
\text { Active evaluation, Wide Diffusion }\end{array}$ & Selection \\
\hline & Incremental & Manipulation & $\begin{array}{l}\text { Conformance } \\
\text { Passive judgement, Narrow Diffusion }\end{array}$ \\
\hline
\end{tabular}




\section{SME Technology Adoption}

SMEs need to actively evaluate legitimacy or illegitimacy of technologies and suppliers within their context, with the creation of new legitimacy criteria. Technologies that are legitimated in context for the SME's are likely to be adopted.

\subsection{Technology Legitimacy}

Legitimacy is defined as congruency of the actions undertaken by an organization with the values, norms, beliefs of the social system to which it belongs [8]. Specifically, technology legitimacy has been defined as the match or mismatch of a technology with institutional structures in peer groups [9]. Any technology which is understood and socially accepted by its market, compatible with existing systems as well as approved by regulators can be said to be legitimized [10]. Besides these, legitimacy is also tied to its contribution to organizational performance [11]. Legitimation is dependent on the characteristics of the organization implementing it (flexibility, preparedness for technological change) and the level of integration and operational change needed. There should be precedents for technology adoption as well as lower resistance to change amongst the decision makers. Precedents indicate existing norms, beliefs, and values regarding the use of related technology. Legitimation can further be used to acquire resources that refine, develop, implement, and commercialize new technologies, impacting its diffusion.

\subsection{Adoption of new technology within organizations}

Technology adoption is the decision to select an innovation as the best available alternative [12] Organizations use multiple criteria to assess the appropriateness of an innovation in a required context. Adoption comes after legitimation of a technology in context. This includes the successful implementation with peers in the same industry or value chain. Thus, adoption of an innovation is dependent on the conformance to an existing category by the members of a social system and it is driven by peer influence [13],[12].

\footnotetext{
${ }^{1}$ Bleeding edge innovations are innovations that are untested, experimental and are highly uncertain.

2 Disruptive technology changes the way businesses operate they are tested but still associated with uncertainty when compared to incumbent technology.
}

Conformance implies an innovation's compatibility with an existing technology or system to ease integration. Some organizations use pilot projects to test innovation at a limited scale or to judge the best amongst multiple alternatives. Alternatives can be multiple ventures using the same technology with some degree of differentiation or between different technologies. Typically, procurement teams have a standard set of criteria including the time to implement, as well as, quality management, previous success criteria, references, capability for technology integration and technology support (Table 4). These criteria legitimize a supplier since it conforms to organizational norms. In cases, where mature alternatives do not exist and disruptive technologies are used, procurement criteria need to be adapted i.e., new norms may have to be created. Disruptive and bleeding edge ${ }^{1}$ innovations are associated with information insufficiency and high uncertainty (Table 5). Such uncertainty causes an ambiguity regarding technology legitimacy. When the technology or innovation cannot conform to an existing category in the social system, a new category must be created [14]. For example: to work with new ventures with disruptive ${ }^{2}$ technologies, organizations include valuation and the stage of startup (series $\mathrm{A} / \mathrm{B} / \mathrm{C}$ etc.) as a qualification criterion. This legitimizes the process of selection even if the technology is disruptive. Other criteria which lend pragmatic legitimacy to the technology are the conformance of the technology solution itself to the organizational need and the relative advantage of disruptive technology over others as well as the disruptive new ventures over other suppliers.

In situations of information insufficiency development of prototypes is a response to ambiguity and uncertainty. This helps with consequential legitimacy. For example: United States (US) government's child welfare services required vendors to rapidly develop prototypes that could be tested as a prequalification. The best performing prototype was perceived as legitimate for the requirement. When faced with uncertainty about the consequences of adoption, organizational decision makers mimic other organizations [15]. This diffusion of technology takes place through idea translation in context [16] Organizations can also gain information about an innovation through vicarious trials [12]. By casting a wide net into a potential sea of disruptive technology suppliers, organizations create a knowledge base on the 
technology's underlying principles, feasibility in context and opportunity. This constitutes an active effort to learn about a technology. Thus, organization decision makers legitimize or de-legitimize a technology in context through greater comprehensibility [8].
Evaluation strategies that SMEs can use to adopt new technologies along with the connection to legitimacy are summarized in a table (Table 6)

Table 4. Legitimation Criteria for vendor procurement.

\begin{tabular}{|l|l|}
\hline Criteria for Selection & Establishing Legitimacy \\
\hline Performance & Previous performance and customer references in a same or similar industry. \\
\hline Compatibility & Compatibility with existing organizational processes, infrastructure, needs. \\
\hline Regulatory & Conforms with existing regulatory standards. \\
\hline Industry & Conforms with existing industry standards. \\
\hline
\end{tabular}

Table 5. Attributes of different levels of technological newness

\begin{tabular}{|l|l|l|l|}
\hline \multirow{2}{*}{ Attributes } & \multicolumn{2}{|c|}{ Technological Newness } \\
\cline { 2 - 4 } & Mature & Disruptive & Bleeding-edge \\
\hline Uncertainty & Low & \multicolumn{1}{|c|}{ High } \\
\hline Risk & Low & Medium-High tail-Technological & $\begin{array}{l}\text { Limited numbers due to } \\
\text { high uncertainty }\end{array}$ \\
\hline Number of suppliers & Few Winners & $\begin{array}{l}\text { Long } \\
\text { Isomorphism and mimetism }\end{array}$ & High \\
\hline Costs Incurred in implementation & High/Low & Low & \\
\hline
\end{tabular}

Table 6. Strategies for SMEs to evaluate technology for adoption and connection to legitimacy

\begin{tabular}{|c|c|c|}
\hline Strategy & Relevance for adoption & Legitimacy attained \\
\hline Supplier Net & $\begin{array}{l}\text { Create a baseline knowledge level by speaking to } \\
\text { multiple potential suppliers. }\end{array}$ & $\begin{array}{l}\text { Cognitive Legitimacy- } \\
\text { Comprehensibility. }\end{array}$ \\
\hline Adapt Criteria & $\begin{array}{l}\text { Change the qualification criteria for disruptive } \\
\text { technology supplier selection. }\end{array}$ & $\begin{array}{l}\text { Pragmatic Legitimacy } \\
\text { Moral Legitimacy- Consequential, } \\
\text { Procedural. }\end{array}$ \\
\hline Mimic and justify & $\begin{array}{l}\text { Select or reject a disruptive technology or a } \\
\text { technology supplier based on adoption decisions by } \\
\text { peers. }\end{array}$ & Cognitive Legitimacy. \\
\hline Vicarious Trials & $\begin{array}{l}\text { Trial by peers helps identify appropriate technology } \\
\text { and technology suppliers. }\end{array}$ & $\begin{array}{l}\text { Cognitive Legitimacy- } \\
\text { Comprehensibility. } \\
\text { Moral Legitimacy -Consequential. }\end{array}$ \\
\hline Prototyping Contest & $\begin{array}{l}\text { Develop a contest catering to the organizational need } \\
\text { and invite suppliers to compete by developing } \\
\text { prototypes. This is done at a subsidized or negligible } \\
\text { cost. Winner is selected for a larger scale } \\
\text { implementation. }\end{array}$ & Cognitive Legitimacy. \\
\hline
\end{tabular}

\section{IoT applications and $\mathrm{SME}^{3}$ case-studies}

To ensure business survival, competitiveness, productivity and safety, SMEs are adopting digital technologies including the internet of things. The implementation of IoT comes with multiple benefits and

\footnotetext{
${ }^{3}$ SMEs are defined as companies that have a headcount of not more than 500 and turnover less than $€ 50$ million- as per EU definition.
}

opportunities such as reduced labor cost, increased customer value, new service lines and business models, predictability in operations and service [17]. COVID-19 has had a greater negative impact on SMEs that lagged in digitalization and digitization, as well SMEs in sectors such as travel and hospitality. Firms that had a higher degree of digitalization were able to minimize and, in some cases, even benefit from the pandemic 
[18]. According to a report by Vodafone in 2021, most digitalized SMEs identified new business opportunities during COVID-19 at more than double the rate of the least digitalized [4].

A literature review was conducted to identify broad academic themes related to SME's IoT adoption during COVID-19. ProQuest was selected as the archive of choice due to availability of required filters as well as greater coverage of search results. The search query "IoT" AND “COVID-19" AND "SME" was used Only completed papers from peer-reviewed scholarly journals were selected. 20 papers mentioned all search terms out of which, 11 papers were found relevant since they discussed the impact of COVID-19 on SMEs IoT adoption. Papers were categorized into broad themes post analysis (Table 7). While COVID-19 has impacted the adoption of IoT technologies by SMEs specifically in use-cases related to compliance with government requirements and remote working, other factors that stimulate it include existing connectivity infrastructure such as broadband, 5G; creating skill infrastructure to upskill staff in digital technology operation and use; investments through government grants or private investors. Some studies discussed strategies SMEs can use to navigate path to digitalization such as collaboration and driving top-down awareness, tools to enable and measure adoption such as contextually designed testing, benchmarking tools. The articles also discussed potential use-cases and consequences of IoT for SMEs.

However, beyond few use-cases, the papers discussed don't cover the current potential of IoT nor do they discuss future use-cases based on technology still under development. These current and future IoT based use-cases that SMEs can implement are described in next section, followed by case-studies.

Table 7. Literature review on SME IoT based digitalization during COVID-19

\begin{tabular}{|c|c|c|}
\hline Themes & Details & Authors \\
\hline $\begin{array}{l}\text { Stimulating loT } \\
\text { Adoption. } \\
\text { (Presence or } \\
\text { absence of } \\
\text { these factors } \\
\text { impacted the } \\
\text { readiness for } \\
\text { and pace of } \\
\text { adoption) }\end{array}$ & $\begin{array}{ll}\text { - } & \text { Digital supply chain skills, skills infrastructure, } \\
\text { - } & \text { Staff upskilling. } \\
\text { - } & \text { BG. } \\
\text { - } & \text { Governand Infrastructure. } \\
\text { - } & \text { Coping with COVID-19. } \\
\text { - } & \text { Pre-COVID digitization. }\end{array}$ & $\begin{array}{ll}\text { - } & \text { Telukdarie, A., Munsamy, M. and Mohlala, } \\
& \text { P., } 2020 \text { [19]. } \\
\text { - Henderson, D., Munday, M. and Roberts, A., } \\
\\
2021 \text { [20]. } \\
\text { Sufian, A.T., Abdullah, B.M., Ateeq, M., } \\
\text { Wah, R. and Clements, D., } 2021 \text { [21]. } \\
\text { - Bellandi, M., 2020 [22]. } \\
\text { - Guo, H., Yang, Z., Huang, R. and Guo, A., } \\
\quad 2020 \text { [18]. } \\
\end{array}$ \\
\hline $\begin{array}{l}\text { Means of } \\
\text { Digitalization. } \\
\text { (Strategies and } \\
\text { Tools that } \\
\text { enable and } \\
\text { measure } \\
\text { digitalization) }\end{array}$ & $\begin{array}{l}\text { Strategies: } \\
\text { - } \quad \text { Collaboration with Universities for R\&D - } \\
\text { Knowledge Transfer Partnerships. } \\
\text { - } \quad \text { Collaboration with key stakeholders. } \\
\text { - } \quad \text { Governance to drive top-down awareness. } \\
\text { - } \quad \text { Private-Public complementary intervention. } \\
\text { Tools: } \\
\text { - } \quad \text { Industrial Internet Playground and Shadow } \\
\text { - } \quad \text { Snfrastructure to implement and evaluate PoCs } \\
\quad \text { technologio Analysis for selecting most optimized } \\
\text { - Six Gear Roadmap and Benchmarking Tool for } \\
\text { execution and measurement. }\end{array}$ & $\begin{array}{ll}\text { - } & \text { Lepore, D., Micozzi, A. and Spigarelli, F., } \\
& 2021 \text { [23]. } \\
\text { - } & \text { Sufian, A.T., Abdullah, B.M., Ateeq, M., } \\
& \text { Wah, R. and Clements, D., } 2021 \text { [21]. } \\
\text { - } \quad \text { Bellandi, M., } 2020 \text { [22]. } \\
\text { - } \quad \text { Gerlitz, L., Meyer, C., Meyer, C., Prause, G. } \\
\text { and Prause, G., } 2021 \text { [24]. } \\
\text { - } \quad \text { Henderson, D., Munday, M. and Roberts, A., } \\
2021 \text { [20]. } \\
\text { - } \\
\text { Aagaard, A., Presser, M., Collins, T., } \\
\text { Beliatis, M., Skou, A.K. and Jakobsen, E.M., } \\
\text { 2021 [25]. } \\
\text { Guo, H., Yang, Z., Huang, R. and Guo, A., } \\
\text { 2020 [18]. }\end{array}$ \\
\hline $\begin{array}{l}\text { Use-cases of } \\
\text { loT } \\
\text { (Situation } \\
\text { requiring } \\
\text { potential usage } \\
\text { of loT) }\end{array}$ & $\begin{array}{l}\text { - } \text { IoT sensors can be used on their own and in } \\
\text { combination with drones applied for surveillance } \\
\text { and environmental Monitoring. } \\
\text { - } \quad \text { Remote Monitoring Patients at home. } \\
\text { Robotics for repetitive tasks and ensure social } \\
\text { distancing, Collaborative Robots. } \\
\text { - Smart Supply Chains and Supply Chain } \\
\text { Planning. } \\
\text { - Digital Twin. }\end{array}$ & $\begin{array}{ll} & \text { Lepore, D., Micozzi, A. and Spigarelli, F., } \\
& 2021 \text { [23]. } \\
\text { - } & \text { Dzhuguryan, T. and Deja, A., } 2021 \text { [26]. } \\
\text { - } & \text { Sufian, A.T., Abdullah, B.M., Ateeq, M., } \\
& \text { Wah, R. and Clements, D., } 2021 \text { [21]. } \\
\text { - } \quad \text { Kim, H.K. and Lee, C.W., } 2021 \text { [27]. } \\
\text { - } \quad \text { Guo, H., Yang, Z., Huang, R. and Guo, A., } \\
2020 \text { [18]. }\end{array}$ \\
\hline
\end{tabular}




\begin{tabular}{|c|c|c|}
\hline $\begin{array}{l}\text { Effects of } \\
\text { Digitalization } \\
\text { (Measuring the } \\
\text { effects, its } \\
\text { benefits, and } \\
\text { consequences) }\end{array}$ & $\begin{array}{l}\text { Tools: } \\
\text { - } \quad \text { Ex Post Digital maturity assessment. } \\
\text { - Ongoing research to analyze effects. } \\
\text { Outcomes: } \\
\text { - } \quad \text { Change in job structures- possible } \\
\text { unemployment. } \\
\text { - Formation of social capital- supply chain } \\
\text { performance. } \\
\text { Increased gap between large companies and } \\
\quad \text { SMEs. }\end{array}$ & $\begin{array}{ll}\text { - } & \text { Henderson, D., Munday, M. and Roberts, A., } \\
& 2021 \text { [20]. } \\
\text { - } & \text { Grenčíková, A., Kordoš, M., Bartek, J. and } \\
& \text { Berkovič, V., 2021 [28]. } \\
\text { - } \quad \text { Kim, H.K. and Lee, C.W., } 2021 \text { [27]. } \\
\text { - } \quad \text { Bellandi, M., } 2020 \text { [22]. }\end{array}$ \\
\hline
\end{tabular}

\subsection{IoT Applications}

Use-cases were identified from academic and nonacademic sources based on IoT's current capabilities and under development that mitigate pandemic related challenges. They were categorized into safety and compliance (enabling businesses ensure employee and customer safety as well as adherence to defined protocols), operations (ensuring business continuity) and customer experience.

4.1.1 Safety and Compliance. Drones can be used for surveillance and disinfection of large areas such as factories, shipyards to ensure required compliance protocols are being followed. Drone-based images and videos can also be used to assure customers of required measures being followed inside SME facility.

Cleaning robots fitted with ultraviolet (UV) light can be used to de-contaminate enclosed spaces [29]. This reduces the risk for cleaning staff. It can also be used to trigger alerts on crowd gathering, mask deviations and below threshold physical distancing. Robots can be used for collection and processing of medical waste for medical assistant safety [30].

Facial recognition in public areas can be used to track and contain the spread [31]. Contact tracing and clustering can also be accomplished through real time location updates collected from IoT systems and interconnection of medical and health systems through IoT [31]. Within facilities use of contact tracing through wearables can be used to identify at-risk employees and COVID-19 hotspots due to exposure to symptomatic personnel. Number of individuals within closed spaces can be limited using beacons or sensor-based counters. Thermal sensor systems can limit the entry of suspected infected individuals. IoT wearables or RFID or BLE enabled tags can be used to surveil worker movement for social distancing adherence across industries such as IT, banking, retail, or manufacturing. Violations can be communicated to employees over wearables or SMS/Emails. IoT based surveillance can be used to inform managers and supervisors about most used surfaces triggering alerts for sanitization.

4.1.2 Operations. Drones or autonomous robot vehicles can be used for contactless grocery, food or medicine delivery. Telepresence robots have cameras, sensors, and video screen to allow remote teleconferencing between doctors and patients for remote healthcare as well as take the temperatures of the patients and measure the blood pressure [29]. RFID enabled robots to have been used to distribute medicines to medical teams, as has been done at Geisinger [30]. In hospitality, robots are used for the delivery of food and medicines for quarantined guests and staff in hotels.

Digital twin can be used to reduce frequency of inperson monitoring in industries like healthcare or mining using data collected from sensors embedded in products, machines, operations, or persons. Hospitals can use it to aggregate and analyze data related to patient health to verify the benefit of a respirator use for individual patients. Digital twins help predict failures as well as provide end to end visibility of processes. Nurses can help with patient's early diagnosis and care using augmented reality (AR) enabled through IoT while being assisted remotely by doctors [30]. This is being used in heavy manufacturing industries for machine diagnosis and maintenance. IoT is being used for monitoring of vaccine supply chains to prevent counterfeits and track the ambient conditions through temperature, pressure, and vibration sensors. Similarly, it can be used by small and medium businesses to ensure provenance of products across their supply chains.

4.1.3 Customer Experience. Aerial imagery captured through drones can be used to create 3D (three dimensional) virtual tours for tourism and retail industries [32]. Robots can be used for welcoming, registering and taking orders from customers in the hospitality and retail industries. In fashion, a combination of AR, IoT and artificial intelligence (AI) can be used to scan a customer's physical dimensions as well as enable a virtual trial of clothing. Haptic sensors are being used to develop a 'feel' dimension which customers can experience while shopping for objects from their homes [33]. Within small retail stores contactless checkout helps with the safer customer experience. For consumer research, brands use electroencephalogram (EEG) along with computer vision to analyze consumer reaction to new products, advertisements, or promotional display units. In the 
future, use of brain machine interface that helps record neural activity at a higher speed and resolution may also be used to collect data for better customer experience.

\subsection{SME Case-Studies of IoT Adoption during COVID-19}

Case-studies across industries and geographies were selected provided they were verified through more than one source (through additional news and website coverage or confirmed by the actors quoted in the articles), they are current to the pandemic and relevant to the purpose of this paper. The references for these case studies are based on non-academic secondary sources since there was insufficient academic data.

4.2.1 Open Solutions for health. Open solutions for health are a Health information technology (IT) services SME based in the Commonwealth of Dominica. They help businesses meet government compliance protocols for safely reopening. They helped Dominican travel and tourism companies adopt IoT by recommending the implementation of Feverwarn, an end-to-end visitor, staff, customer screening solution. Feverwarn solution can use existing thermal scanners as well as provide its own thermal scanners. The visitor uses an app to submit the visitor waiver form for authorization to enter. Once the form is submitted the visitor receives a quick response $(\mathrm{QR})$ code on the phone which they scan with the FeverWarn reader to get the temperature scanned. For temperature scanning, the visitor places a fist under the infrared scanner that measures temperature. The device then stores the QR code with the person's temperature for compliance perspective. Further, in cases where the temperature is beyond the threshold, entry within the facility may be curtailed using a smart lock solution. The thermal scanner uses sensors arranged in a spatial geometric format along with an AI algorithm to filter out ambient temperature conditions and sunlight to prevent errors. It enables self-service temperature check, removing the need for personnel to perform these checks [34].

4.2.2 Gobecke Bakery. With the easing of the lockdown, Germany based Gobecke bakery wanted to ensure safety for all staff members. All employees are provided Bluetooth enabled badges which interact with beacons in the store, and emit alarms if employees come closer than 1.5 meters to each other for more than 15 seconds. When the alarm goes off, an incident is registered on the IoT platform which can be accessed through a mobile or a tablet app. The app can be accessed by the promoters who can discuss it with the staff. The data is also used to keep track who employees were in contact with incase they fall ill [35].

4.2.3 Island Grill. Island Grill restaurant based in USA, has deployed a robotic server to serve customers in the restaurant due to lack of labor available post lockdown. The robot is equipped with light detection and ranging (LIDAR,) machine vision, infrared, touch, and depth sensors for creation of indoor path plans using SLAM (Simultaneous localization and mapping) algorithms. The servers can input the order through the robot's touchscreen while the robot carries the order from the kitchen back to the customer's table. The server then offloads the plates from the robot and loads the plates back when the customers are finished with the meal. The robot then carries the plates back to the cleaning station. The robot is also equipped with a voice interface to accept voice commands as well as greet the customers [36].

4.2.4 Animal Liberation Kitchen. Animal Liberation Kitchen signed up with a delivery robot that can deliver food within a 2-mile radius. The robot is fitted with cameras and global positioning system (GPS) and controlled remotely for navigation [37].

4.2.5. Welcome Mart. Welcome mart is a mom-andpop store based in India. The store has implemented sound wave based contactless payment solution. The solution comprises a hardware device which the customer taps using their phone. A sound carrying encrypted data is emitted which is valid for a period. The sound contains the merchant identity data. A pop up on the phone screen signals the customer to authenticate, enter the amount to be paid and complete the transaction. It does not require pairing between devices or any internet access [38].

4.2.6. Promess. Promess is a manufacturer of turnkey process monitoring and testing systems. They develop electric press workstations and because of the pandemic have added additional functionalities to it. One being the addition of cameras that can measure parts to eliminate need for a separate gauging station. The camera is also used to understand part orientation thus enabling automatic pick up from multiple parts. In addition, they have incorporated cobots for part offloading and onloading. This contributes to social distancing [39].

4.2.7. Versailles Showroom. Versailles Showroom is a luxury furniture store based in USA that used aerial photos captured by a drone as well as 3D imaging to create a virtual store experience for the store's customers and helped it maintain sales by simulating the experience of shopping in person [32].

The case studies and applications indicate IoT enabled solutions which are currently being adopted by SMEs, that are not yet adopted and solutions for which technology is still being developed and tested. IoT based solutions implemented as a response to COVID-19 are preventative or focused on maintaining process efficiency. Accordingly, they experience marginal benefits through changes to business models [40]. 


\subsection{Consequences}

COVID-19 has increased the pace of IoT adoption [41], it has also accelerated awareness related to issues accompanying it. These issues may de-legitimize the technology in the eyes of the SMEs and their customers/employees. To make IoT meaningful for stakeholders, IoT systems should be examined through social, technical, and economic lenses while being developed, evaluated and deployed [42]. Thus, there is a dialectical relationship between IoT developments and their value creation and nurturing [42].

Direct economic value through new IoT based business models can be reaped in the longer term [24] and current SME efforts are aligned towards efficiency gains with a transactional change to the business models. From a social value perspective, IoT can help SMEs comply with COVID-19 safety measures, as well as resuming or continuing business operations. At the same time technology should inspire trust by ensuring privacy and security to enable resiliency and acceptability [42]. Technical values of IoT are associated with the lack of interoperability between different IoT solutions implemented in the same business by different vendors as well as integration to existing IT systems. SMEs adopting technology need to be aware of all possibilities associated with it. Such knowledge can be provided by the governance bodies, third-party consultants, or the vendors. Immediate concerns related to IoT adoption are as follows:

4.3.1 Security. IoT comprises multiple technologies and protocols each with vulnerabilities. An IoT device can be installed and hacked into from anywhere to capture data and control systems. Cyber-epistemic attacks cause the disruption of an IoT system through the manipulation of sensor devices by malicious actors [43]. IoT is also connected to IT systems adding more vulnerability. To illustrate, recently, there was a hack into a water supply plant in the USA using an application installed in a computer connected to the plant, the hacker tried to raise the level of lye in the water [44]. Similarly, a gas pipeline was closed since they could not access pipeline monitoring sensor data due to a ransomware attack on its IT systems [45].

4.3.2 Privacy and Surveillance. There is no clear interface between the sensor and the user. Users are not made aware of, nor given a choice on the collection and use of their data in IoT systems. Moreover, techniques like cross intelligence extraction [46] can be implemented on data computed by applications in the cloud, different information on the same user can be collected by separate sensors and processed by the same applications thus de-anonymizing user's data. Unlike the internet, notice and choice for users operating within IoT context is difficult to implement. With multiple actors operating in an IoT ecosystem that can access this data, transparency is needed in terms of who can access the data, amount of data collected within a specific context and entity responsible for its usage [47]. Contact tracing and facial recognition solutions intrusively enable connection of individual users with their online profiles. Governments can take the opportunity of using such technologies to collect data related to citizen location and activity [48].

4.3.3 Labor and Employment. SMEs play an important role in job creation, for example, in the EU, SMEs are credited with $85 \%$ of all new jobs [49]. Most SMEs that adopt digital also have had to invest in upskilling employees for digital skills [19], [20]. However, there is a likelihood of increase in unemployed labor force due to change in labor demand [50]. There also exists a gap in hardware related technical skills especially in industries such as food and pharmaceuticals where the devices cannot be easily embedded while ensuring quality and safety. Designing and controlling the IoT infrastructure remains a challenge [51]. Changes in the broader labor landscape will require an intervention from the policy makers to secure future skills and help SMEs cope with the change. These complex transitions require time to take effect [41].

\section{Conclusion}

The paper conceptualizes role of COVID-19 as an exogenous force for creating new legitimacy criteria as well on adoption and diffusion within and outside social systems. However, the paper does not discuss in detail concepts such as disruptive innovations and bleeding edge innovations. The paper provides key takeaways for SMEs in terms of decision-making strategies and tools that can help them reduce information insufficiency and uncertainty as they embark on digitalization. These strategies also help SMEs in their attempt to legitimize technologies within their organizations as well as with external stakeholders. The paper also covers clear examples in the form of IoT applications and casestudies which SMEs can adopt during the pandemic. It covers consequences related to privacy, security, surveillance, and labor that they can try to mitigate. For policymakers, the paper provides evidence on how IoT can be used by SMEs to ensure compliance to safety, business operation continuity as well as provide a better customer experience. Policy makers can use the strategies and tools and guide SMEs through best practices for technology selection. They can test widely diffused use-cases such as robots used by Animal liberation kitchen further development and benchmark future solutions. The paper also covers specific tactics for policy such as public-private intervention, enabling 
collaboration with universities and providing grants, that can benefit SMEs. Additionally, policy makers can use the results from the literature review to create an IoT readiness index. For academicians, the use-cases and case-studies can be examined empirically based on the UTAUT2 model (Venkatesh, Thong and Xu., 2012) from a decision maker perspective. In organization studies, SME's organizing during, and post pandemic can be examined through action-net (Czarniawska., 2010) approach where actions include selection, adoption that led to technology systems as well as actions executed by technology systems that lead to organizations.

\section{Acknowledgements}

This paper is part of the European Union's Horizon 2020 research and innovation programme under the Marie Skłodowska-Curie grant agreement No 860364. It reflects only the authors' view and the Agency is not responsible for any use that may be made of the information it contains

\section{References}

[1] 1] O'Halloran, J., 2020. Industrial IoT connections to reach 37 billion by 2025. [online] ComputerWeekly.com. Available at: https://www.computerweekly.com/news/252491495/Ind ustrial-IoT-connections-to-reach-37-billion-by-2025.

[2] Tost, L.P., 2011. An integrative model of legitimacy judgments. Academy of management review, 36(4), pp.686-710.

[3] Micelotta, E., Lounsbury, M. and Greenwood, R., 2017. Pathways of institutional change: An integrative review and research agenda. Journal of Management, 43(6), pp.1885-1910.

[4] 2020. SME Digitalisation - charting a course towards resilience and recovery. [online] Vodafone, Available at: $<$ https://www.vodafone.com/content/dam/vodcom/files/ vdf_files_2020/pdfs/sme-digitalisation.pdf >

[5] Moore, G., 2014. Crossing the chasm. 3rd ed. HarperCollins.

[6] Jansma, S.R., Gosselt, J.F., Kuipers, K. and de Jong, M.D., 2020. Technology legitimation in the public discourse: applying the pillars of legitimacy on GM food. Technology Analysis \& Strategic Management, 32(2), pp.195-207.

[7] Kuratko, D.F., Fisher, G., Bloodgood, J.M. and Hornsby, J.S., 2017. The paradox of new venture legitimation within an entrepreneurial ecosystem. Small Business Economics, 49(1), pp.119-140.

[8] Suchman, M. C. (1995) 'Managing Legitimacy: Strategic and Institutional Approaches', Academy of Management Review, 20(3), pp. 571-610. doi: 10.5465/amr.1995.9508080331

[9] Binz, C., Harris-Lovett, S., Kiparsky, M., Sedlak, D.L. and Truffer, B., 2016. The thorny road to technology
legitimation-Institutional work for potable water reuse in California. Technological Forecasting and Social Change, 103, pp.249-263.

[10] Markard, J., Wirth, S. and Truffer, B., 2016. Institutional dynamics and technology legitimacy-A framework and a case study on biogas technology. Research Policy, 45(1), pp.330-344.

[11] Ren, M., 2019. Why technology adoption succeeds or fails: an exploration from the perspective of intraorganizational legitimacy. The Journal of Chinese Sociology, 6(1), pp.1-26.

[12] Rogers, E. M. (2003) Diffusion of innovations. 5th edn. New York: Free Press

[13] Rossman, G., 2014. The Diffusion of the Legitimate and the Diffusion of Legitimacy. Sociological Science, 1, p.49.

[14] Zimmerman, M. A. and Zeitz, G. J. (2002) 'Beyond survival: Achieving new venture growth by building legitimacy', Academy of Management Review, 27(3), pp. 414-431. doi: 10.5465/AMR.2002.7389921.

[15] Kumar Sarma, S., 2017. Theorization of New Practices in Emerging Organizational Fields. Vikalpa, 42(3), pp.131-144.

[16] Sahlin-Andersson, K. (2012) 'Imitating by Editing Success: The Construction of Organizational Fields', Translating Organizational Change. doi: 10.1515/9783110879735.69

[17] Akpan, I.J., Udoh, E.A.P. and Adebisi, B., 2020. Small business awareness and adoption of state-of-the-art technologies in emerging and developing markets, and lessons from the COVID-19 pandemic. Journal of Small Business \& Entrepreneurship, pp.1-18.

[18] Guo, H., Yang, Z., Huang, R. and Guo, A., 2020. The digitalization and public crisis responses of small and medium enterprises: Implications from a COVID-19 survey. Frontiers of Business Research in China, 14(1), pp.1-25.

[19] Telukdarie, A., Munsamy, M. and Mohlala, P., 2020. Analysis of the Impact of COVID-19 on the Food and Beverages Manufacturing Sector. Sustainability, 12(22), p.9331.

[20] Henderson, D., Munday, M. and Roberts, A., 2021. The regional consequences of new digital infrastructure: can Welsh SMEs gain an edge from access and adoption of superfast broadband? National Institute Economic Review, 255, pp.42-55.

[21] Sufian, A.T., Abdullah, B.M., Ateeq, M., Wah, R. and Clements, D., 2021. Six-Gear Roadmap towards the Smart Factory. Applied Sciences, 11(8), p.3568.

[22] Bellandi, M., 2020. Some Notes on the Impacts of Covid19 on Italian SME Productive Systems. Symphonya. Emerging Issues in Management, (2), pp.63-72.

[23] Lepore, D., Micozzi, A. and Spigarelli, F., 2021. Industry 4.0 Accelerating Sustainable Manufacturing in the COVID-19 Era: Assessing the Readiness and Responsiveness of Italian Regions. Sustainability, 13(5), p.2670.

[24] Gerlitz, L., Meyer, C., Meyer, C., Prause, G. and Prause, G., 2021. Marketing and branding strategy for the South Baltic Sea Region: reinforcing regional innovation in SMEs through cross-border collaboration models in the 
age of transformation. Entrepreneurship and Sustainability Issues, 8(4), pp.467-487.

[25] Aagaard, A., Presser, M., Collins, T., Beliatis, M., Skou, A.K. and Jakobsen, E.M., 2021. The Role of Digital Maturity Assessment in Technology Interventions with Industrial Internet Playground. Electronics, 10(10), p.1134.

[26] Dzhuguryan, T. and Deja, A., 2021. Sustainable Waste Management for a City Multifloor Manufacturing Cluster: A Framework for Designing a Smart Supply Chain. Sustainability, 13(3), p.1540.

[27] Kim, H.K. and Lee, C.W., 2021. Relationships among healthcare digitalization, social capital, and supply chain performance in the healthcare manufacturing industry. International Journal of Environmental Research and Public Health, 18(4), p.1417.

[28] Grenčíková, A., Kordoš, M., Bartek, J. and Berkovič, V., 2021. The Impact of the Industry 4.0 Concept on Slovak Business Sustainability within the Issue of the Pandemic Outbreak. Sustainability, 13(9), p.4975.

[29] Jain, R., Gupta, M., Garg, K. and Gupta, A., 2021. Robotics and Drone-Based Solution for the Impact of COVID-19 Worldwide Using AI and IoT. Emerging Technologies for Battling Covid-19: Applications and Innovations, pp.139-156.

[30] Ahad, M.A., Paiva, S., Tripathi, G., Haq, Z.A., Nafis, M.T. and Feroz, N., 2021. Big Data and Modern-Day Technologies in COVID-19 Pandemic: Opportunities, Challenges, and Future Avenues. Emerging Technologies for Battling Covid-19: Applications and Innovations, pp.79-106.

[31] Abd El-Aziz, A.A., Khalifa, N.E.M., Darwish, A. and Hassanien, A.E., 2021. The Role of Emerging Technologies for Combating COVID-19 Pandemic.

[32] Dukowitz, Z., 2021. Three Ways Drones Can Help Small Businesses. [online] UAV Coach. Available at: <https://uavcoach.com/drones-small-businesses/>

[33] Cordis.europa.eu. 2021. CORDIS European Commission Available https://cordis.europa.eu/project/rcn/72298/it

[34] FeverWarn Body Temperature Scanning Delivers Waiver Integration for Turnkey Workplace and Public Health Safety Solution. (2021). PR Newswire. [online] Available at:https://www.prnewswire.com/newsreleases/feverwarn-body-temperature-scanning-deliverswaiver-integration-for-turnkey-workplace-and-publichealth-safety-solution-301254196.html

[35] Twentyman, J. (2020, August 3). IoT is icing on the cake for Göbecke Bakery's back-to-work strategy. diginomica. https://diginomica.com/iot-icing-cakegobecke-bakerys-back-work-strategy

[36] Bongard, K., 2021. Ocean City Restaurant Employs Robot Server Amid Staff Shortage. [online] Ocean City, NJ Patch. Available at: https://patch.com/newjersey/oceancity/ocean-city-restaurant-employs-robotserver-amid-staff-shortage

[37] Trapunski, R., 2021. Who's behind Toronto's cute pink delivery robots?. NOW Magazine. Available at: https://nowtoronto.com/food-and-drink/torontoembraces-the-pink-robots
[38] ToneTag Success Stories: Welcome Mart, Bangalore (RetailPod) ToneTag. (2020). ToneTag. https://www.tonetag.com/tonetag-blog/tonetag-successstories-welcome-mart-bangalore-retailpod

[39] Sinkora, E., 2021. Automation in the Age of COVID-19. Sme.org. Available at https://www.sme.org/technologies/articles/2021/march/a utomation-in-the-age-of-covid-19/

[40] Linz, C., 2021. How to transform your business model for a post-COVID future. World Economic Forum. Available at: https://www.weforum.org/agenda/2020/11/transformbusiness-model-post-covid-future/

[41] Stahie, S., 2021. COVID-19 Pandemic Increased IoT Adoption, Research Finds. Bitdefender. Available at: https://www.bitdefender.com/box/blog/iot-news/covid19-pandemic-increased-iot-adoption-research-finds

[42] Nicolescu, R., Huth, M., Radanliev, P. and De Roure, D., 2018. Mapping the values of IoT. Journal of Information Technology, 33(4), pp.345-360.

[43] Smart, Paul R. and Robert W. Clowes. 2021. "Intellectual Virtues and Internet-Extended Knowledge." Social Epistemology Review and Reply Collective 10 (1): 7-21. https://wp.me/p1Bfg0-5AY.

[44] How Hackers Tried to Add Dangerous Lye into a City's Water Supply. (n.d.). Scientific American. https://www.scientificamerican.com/article/howhackers-tried-to-add-dangerous-lye-into-a-citys-watersupply/

[45] Tidy, J., 2021. Colonial hack: How did cyber-attackers shut off pipeline? [online] BBC News. Available at: <https://www.bbc.co.uk/news/technology-57063636>

[46] Maheswaran, M. and Misra, S., 2015, December. Towards a social governance framework for Internet of Things. In 2015 IEEE 2nd World Forum on Internet of Things (WF-IoT) (pp. 801-806). IEEE.

[47] Almeida, V.A., Doneda, D. and Monteiro, M., 2015. Governance challenges for the Internet of Things. IEEE Internet Computing, 19(4), pp.56-59.

[48] Munro, K. and Cave, D., 2021. Covid-19 is accelerating the surveillance state. The Strategist. Available at: https://www.aspistrategist.org.au/covid-19-isaccelerating-the-surveillance-state/

[49] European Commission - European Commission. https://europa.eu/rapid/press-release_IP-12-20_en.htm

[50] Acemoglu, D. and Restrepo, P., 2019. Automation and new tasks: How technology displaces and reinstates labor. Journal of Economic Perspectives, 33(2), pp.3-30.

[51] Aamer, A.M., Al-Awlaqi, M.A., Affia, I., Arumsari, S. and Mandahawi, N., 2021. The internet of things in the food supply chain: adoption challenges. Benchmarking: An International Journal.

[52] Venkatesh, V, Thong, J. L. \& Xu, X. (2012). Consumer acceptance and use of information Technology: extending the unified theory of acceptance and use of technology. MIS Quarterly. 36(1), pp. 157-178.

[53] Czarniawska, B. (2010), 'Going back to go forward: On studying organizing in action nets'. In T. Hernes, \& S. Maitlis (eds.), Process, sensemaking, and organizing: Oxford: Oxford University Press, pp. 140-160. 